\title{
FAKTOR-FAKTOR YANG BERHUBUNGAN DENGAN WAKTU MENYUSUI PERTAMA KALI PADA BAYI BARU LAHIR DI RSUD MERAUKE
}

\author{
Hermelina Yaru ${ }^{1)}$ Ngadiyono $^{2)}$ Nur Khafidhoh $^{3)}$ \\ E-mail address : hermelinayaru@gmail.com
}

\begin{abstract}
Advantages of Early Breastfeeding Initiation is to get food with quality and quantity. The purpose of this study to determine the factors associated with the time of breastfeeding the firstfirst time in newborns at the Regional General Hospital (RSUD).

This research design using descriptive method of quantitative research with cross sectional approach with accidental sampling technique. The sample is 60 respondents. Data were collected in the post partum room of normal post-partum mothers with normalborn infants at RSUD Merauke. Independent variable is mother's age, mother's education, mother's parity, mother's knowledge, type of delivery and support of health officer. The dependent variable is the first feeding time in the newborn.

The results showed that the factors that influence the time of first breastfeeding in the newborn is the type of labor ( $\mathrm{p}$ value 0.00 ) while the non-influencing factors are maternal age ( $\mathrm{p}$ value 0.765 ), maternal education ( $\mathrm{p}$ value 0.390$)$, maternal parity value 0.12 ) maternal knowledge ( $\mathrm{p}$ value 0,528 ) and health officer support ( $\mathrm{p}$ value 0.19 ).
\end{abstract}

Keywords: Early Initiation of Breastfeeding; Newborns

1) RSUD Merauke

2)3) Poltekkes Kemenkes Semarang

\section{Pendahuluan}

Angka kematian bayi (AKB) atau Infant mortality rate merupakan indikator yang lazim digunakan untuk menentukan derajat kesehatan masyarakat baik pada tatanan propinsi maupun nasional.Angka kematian bayi (AKB) merujuk pada jumlah bayi yang meninggal pada fase antara kelahiran hingga bayi belum mencapai umur 1 tahun per 1.000 kelahiran hidup.

Saat ini (AKB) di Indonesia adalah tertinggi dibandingkan dengan negara ASEAN lainnya. Menurut data survei demografi dan kesehatan indonesia (SDKI) 2007, Angka kematian bayi(AKB) di Indonesia 34 per 1000 kelahiran hidup (Depkes,2009) Bila di rincikan 157.000 bayi meninggal dunia pertahun atau 430 bayi meninggal dunia perhari (Depkes, 2015). Sementara hingga pertengahan tahun atau semester satu 2017 tercatat sebanyak 10.294 kasus kematian bayi. (Kemenkes, 2017). Salah satu tujuan MDG's yaitu mengakhiri kematian bayi dan balita yang dapat dicegah, dengan menurunkan Angka Kematian Neonatal hingga 12 per $1.000 \mathrm{KH}$ (Indikator Kesehatan SDG's, 2017). Angka kematian bayi di sembilan kabupaten di Provinsi Papua pada tahun 2016 masih cukup tinggi, yakni 20 kematian per 1000 kelahiran bayi. Rumah Sakit Umum Daerah Merauke adalah satu-satunya rumah sakit rujukan di Papua bagian selatan, Rumah Sakit Umum Daerah Merauke 
menerima pasien rujukan dari dari tiga Kabupaten Pemekaran dan puskesmaspuskesmas yang ada di Kabupaten Merauke, dengan jumlah persalinan normal dan sectio caesarea yang meningkat di tahun 2017 dalam tiga bulan terahkir, bulan Juni untuk ibu melahirkan normal sebanyak 144 atau $67 \%$ ibu dan yang sectio caesarea sebanyak $68 \mathrm{ibu}$ atau 32,07\%, bulan Juli ibu yang nelahirkan normal 130 atau $71,03 \%$, sedangkan yang sectio caesarea sebanyak 53 ibu atau 28,96\%, dalam bulan Agustus ibu yang melahikan normal 146 ibu atau 72,63\% dan yang sectiocaesarea sebanyak 55 ibu atau 27,36\%.kelahiran atau sekitar $4,27 \%$, sedangkan tahun 2017 terdapat 83 bayi yang meninggal dari 1655 kelahiran atau sekitar 5,01\%.

Secara teori keuntungan Inisiasi Menyusu Dini untuk bayi adalah mendapatkan makanan dengan kualitas dan kuantitas optimal agar kolostum segera keluar yang disesuaikan dengan kebutuhan bayi, serta memberikan kesehatan bayi dengan kekebalan pasif yang segera kepada bayi, karena kolostrum merupakan imunisasi pertama bagi bayi, sehingga bayi lebih kebal terhadap infeksi dan penyakit.(menurut penelitian Fauziah, 2009).

Penanganan yang dilakukan untuk mengurangi kematian bayi dan kesakitan pada bayi di RSUD Merauke, yaitu dengan menerapkan program Inisiasi Menyusu Dini sejak tahun 2015, pada ibu bersalin, namun belum begitu efektif. Menurut penelitian Fauziah salah satunya disebabkan oleh bu menolak dilakukan IMD, dengan alasan merasa tidak nyaman.

\section{Metode penelitian}

Penelitian ini merupakan penelitian kuantitatif dengan desain penelitian cross sectional. Penelitian cross sectional adalah jenis penelitian yang menekankan waktu pengukuran/ observasi data variabel independen dan dependen hanya satu kali pada suatu saat. Pada penelitian jenis variabel independen dan dependen dinilai secara simultan pada satu saat, jadi tidak ada tindak lanjut. Tentunya tidak semua subyek penelitian harus diobservasi pada hari atau waktu yang sama, akan tetapi baik variabel independen maupun variabel dependen dinilai hanya satu kali saja. Dengan studi ini akan diperoleh prevalensi atau efek suatu fenomena (variabel dependen) dihubungkan dengan penyebab (variabel independen) (Nursalam, 2003).

Teknik sampling adalah proses seleksi sampel yang digunakan dalam penelitian dari populasi yang ada, sehingga jumlah sampel akan mewakili keseluruhan populasi yang ada (Hidayat, 2008). Dalam penelitian ini Sampling yaitu secara Accidental Samping, artinyapengambilan sampel didasarkan pada kenyataan bahwa mereka kebetulan muncul. Pengumpulan data adalah suatu proses pendekatan kepada subyek dan proses pengumpulan karakteristik subyek yang diperlukan dalam penelitian (Nursalam, 2003).

Pengmpulan data dilakukan di Ruang Bersalin RSUD Merauke, dengan proses sebagai berikut (25) Setelah proposal mendapat persetujuan dari pembimbing akademi, dilanjutkan dengan membuat surat permohonan dari Jurusan Kebidanan kepada Direktur RSUD Merauke dan bagian Keperawatan RSUD Merauke (26) 
Setelah mendapat persetujuan dari Keperawatan, peneliti menyerahkan surat permohonan tersebut kepada kepala ruangan bersalin RSUD Merauke.(27) Setelah peneliti meminta ijin kepada kepala ruangan bersalin RSUD Merauke untuk melihat data ibu-ibu yang akan bersalin perhari.(28) Melakukan pengambilan sampel dengan teknik Accidental Sampling.

Penelitian ini dilakukan di RSUD Merauke, pada bulan April sampai Mei 2018. Populasi dalam penelitian ini adalah semua semua ibu-ibu post partum di RSUD Merauke dengan ratarata 1 bulan terakhir yaitu 150 ibu. Jumlah sampel yang dibutuhkan yaitu sebanyak 60 orang.

Instrumen untuk pengumpulan data pada penelitian meggunakan data primer dan sekunder. Data primer diperoleh melalui observasi dan kuesioner sedangkan data sekunder diperoleh melalui reka medis. Waktu menyusui pertama kali pada bayi baru lahir dan jenis persalinan diperoleh dengan cara observasi. Kuesioner diberikan kepada ibu-ibu post partum saat di ruang nifas untuk diisi dan dilengkapi. Kuesioner selama kehamilan dan persalinan, dan dukungan petugas kesehatan terhadap menyusui dini. Sedangkan data sekunder didapatkan dari rekam medis untuk melihat variabel independen yaitu berat bayi saat lahir. Pada pertanyaan variabel pengetahuan, sikap ibu dan dukungan petugas kesehatan dilakukan proses scoring.

Pengukuran reliabilitas dilakukan dengan cara one shoot time atau pengukuran sekali saja kemudian hasilnya di bandingkan dengan pertanyaan lain atau mengukur korelasi antara jawaban pertanyaan. Pengujian kuesioner tersebut digunakan untuk rumus koefisien reabilitas alpha cronbach. Pengujian dilakukan dengan menguji validitas terlebih dahulu lalu kemudian dilakukan pengujian reliabilitas. Reliabel jika > 0,6 atau 0,7.

\section{Hasil dan Pembahasan}

A. Analisa Univariat

Tabel 1. Umur Ibu

\begin{tabular}{lll} 
Umur & Frekuensi & Presentase \\
\hline Remaja ( 12-25 th) & 17 & 28,3 \\
\hline Dewasa (26-45 th $)$ & 43 & 71,7 \\
\hline Total & 60 & 100 \\
\hline \multicolumn{1}{c}{ Tabel } & 1 & menunjukan bahwa
\end{tabular}

sebagian besar responden berumur dewasa ( 26-45 th) sebanyak 43 orang ( $71,7 \%$ ), dan sebagian lagi berumur remaja ( $12-25$ th) sebanyak 17 orang ( $28,3 \%)$.

Tabel 2. Pendidikan Ibu

\begin{tabular}{lll}
\hline Pendidikan & Frekuensi & Presentase \\
\hline Tidak Tamat SD & 6 & 10 \\
\hline SD & 6 & 10 \\
\hline SMP & 8 & 13,3 \\
\hline SMA & 32 & 53,3 \\
\hline PT & 8 & 13,3 \\
\hline Total & 60 & 100 \\
\hline
\end{tabular}

Tabel 2. menunjukan bahwa sebagian besar pendidikan ibu adalah SMA sebanyak 32 orang ( 53,3\%), sedangkan pendidikan SMP dan Perguruan tinggi sama yaitu sebanyak 8 orang $(13,3 \%)$ dan pendidikan SD dan tidak tamat SD sama yaitu 6 orang ( $10 \%)$.

Tabel 3. Paritas Ibu

\begin{tabular}{|c|c|c|}
\hline Paritas & Frekuensi & Presentase \\
\hline Primipara & 15 & 25 \\
\hline Multipara & 36 & 60 \\
\hline Grande Multi para & 9 & 15 \\
\hline Total & 60 & 100 \\
\hline
\end{tabular}

'Tabel ' 3 ' menunjukan 'bahwa' sebagian besar responden adalah ibu bersalin multipara sebanyak 36 orang ( $60 \%)$, primipara sebanyak 15 ( $25 \%)$ 
dan grandemultipara ada 9 orng ( 15 $\%)$.

Tabel 4. Jenis Persalinan

\begin{tabular}{lll}
\hline Jens Persalinan & Frekulensi & Presentase \\
\hline SC & 19 & 31,7 \\
\hline Spontn & 41 & 68,3 \\
\hline Total & 60 & 100 \\
\hline
\end{tabular}

Berdasarkan tabel 4 menunjukan bahwa jenis perslinan di RSUD Merauke adalah Spontan sebanyak $41(68,3 \%)$ dan SC ada 19 ( $31,7 \%)$.

Tabel 5. Pengetahuan

\begin{tabular}{lll}
\hline Pengetahuan & Freklensi & Presentase \\
\hline Rendah & 36 & 60 \\
\hline Tingoi & 24 & 40 \\
\hline Total & 60 & 100 \\
\hline
\end{tabular}

Tabel 5 menunjukan bahwa tingkat pengetahuan ibu sebagian besar adalah berpengetahuan rendah sebanyak 36 orang ( $60 \%)$, dan perpengetahuan tinggi sebanyak 24 orang ( $40 \%$ ).

Tabel 6. Dukungan Petugas Kesehatan

\begin{tabular}{|c|c|c|}
\hline $\begin{array}{l}\text { Dukungan } \\
\text { Kesehatan }\end{array}$ & Petugas Frekuensi & Presentase \\
\hline Negatif & 43 & 71,7 \\
\hline Positif & 17 & 28,3 \\
\hline Total & 60 & 100 \\
\hline
\end{tabular}

Tabel 6 menunjukan bahwa dukungan petugas kesehatan terhadap IMD sebagian besar adalah negatif yaitu sebanyak $71,7 \%$ dan dukungan positif sebanyak $28,3 \%$.

Tabel 7. Waktu Menyusui Pertama Kali

\begin{tabular}{lll}
\hline Waktu IMD & Frekuensi & Presentase \\
\hline Baik & 39 & 65 \\
\hline Tidak Baik & 21 & 35 \\
\hline Total & 60 & 100 \\
\hline
\end{tabular}

Tabel 7 menunjukan bahwa sebagian besar waktu IMD adalah baik sebanyak $65 \%$, dan yang tidak baik sebanyak $35 \%$

\section{B. Analisa Bivariat}

Tabel 8. Hubungan antara umur ibu dengan waktu menyusui pertama kali pada bayi baru lahir.

\begin{tabular}{|c|c|c|c|c|c|c|c|}
\hline \multirow{3}{*}{ Umur } & \multicolumn{4}{|c|}{ Waktu menyusui Pertama } & \multirow{2}{*}{\multicolumn{2}{|c|}{ Total }} & \multirow{3}{*}{$\begin{array}{c}P \\
\text { value }\end{array}$} \\
\hline & \multicolumn{2}{|c|}{ Baik } & \multicolumn{2}{|c|}{ Tidak Baik } & & & \\
\hline & $\mathrm{f}$ & $\%$ & $\mathrm{~F}$ & $\%$ & $\mathrm{~F}$ & $\%$ & \\
\hline Remaja & 12 & 70,6 & 5 & 29,4 & 17 & 100 & 0,765 \\
\hline Dewasa & 27 & 62,8 & 16 & 37,2 & 43 & 100 & \\
\hline Total & 39 & 65 & 21 & 35 & 60 & 100 & \\
\hline
\end{tabular}

Tabel 8 menunjukkan bahwa umur remaja cenderung waktu menyusui pertamanya baik yaitu sebanyak 70,6 lebih besar dibanding umur dewasa umur dewasa yaitu 62,8 $\%$.

Sedangkan umur dewasa waktu menyusui pertama tidak baik yaitu sebanyak 37,2 \% lebih besar di banding umur remaja yaitu $29,4 \%$. Hasil uji chi square didapatkan nlai $\mathrm{p}$ value $0,765>$ $\alpha$ 0,05 sehingga tdak ada hubungan antara umur dengan waktu menyusui pertama pada bayi baru lahir.

Tabel 9. Hubungan antara pendidikan ibu dengan waktu menyusui pertamakali pada bayi baru lahir.

\begin{tabular}{|c|c|c|c|c|c|c|c|}
\hline \multirow{3}{*}{ Pendidikan } & \multicolumn{4}{|c|}{ Waktu menyusui Pertama } & \multirow{2}{*}{\multicolumn{2}{|c|}{ Total }} & \multirow{3}{*}{$\begin{array}{c}\mathrm{P} \\
\text { value }\end{array}$} \\
\hline & \multicolumn{2}{|c|}{ Baik } & \multicolumn{2}{|c|}{ Tidak Baik } & & & \\
\hline & F & $\%$ & $F$ & $\%$ & F & $\%$ & \\
\hline Rendah & 15 & 75 & 5 & 25 & 20 & 100 & \\
\hline Tinggi & 24 & 60 & 16 & 40 & 40 & 100 & 0,390 \\
\hline Total & 39 & 65 & 21 & 35 & 60 & 100 & \\
\hline
\end{tabular}

Tabel 9 menunjukkan bahwa pendidikan rendah cenderung waktu menyusui pertamanya baik yaitu 
sebanyak $75 \%$ lebih besar dibandingkan pendidikan tinggi yaitu $60 \%$. Sedangan pendidikan tinggi cenderung tidak baik waktu menyusui pertamanya yaitu sebanyak $40 \%$ lebih besar di banding pendidikan rendah yaitu $25 \%$.

Hasil uji chi square didapatkan nlai $\mathrm{p}$ value $0,390>\alpha 0,05$ sehinga tidak ada hubungan antara pendidikan dengan waktu menyusui pertama pada bayi baru lahir.

Tabel 10. Hubungan antara paritas ibu dengan waktu menyusui pertama kali pada bayi baru lahir.

\begin{tabular}{|c|c|c|c|c|c|c|c|}
\hline \multirow{3}{*}{ Paritas } & \multicolumn{4}{|c|}{ Waktu menyusui Pertama } & \multirow{2}{*}{\multicolumn{2}{|c|}{ Total }} & \multirow{3}{*}{$\begin{array}{c}P \\
\text { value }\end{array}$} \\
\hline & \multicolumn{2}{|c|}{ Baik } & \multicolumn{2}{|c|}{ Tidak Baik } & & & \\
\hline & $\mathrm{F}$ & $\%$ & $\mathrm{~F}$ & $\%$ & F & $\%$ & \\
\hline Primipara & 7 & 46,7 & 8 & 53,3 & 15 & 100 & \\
\hline Multipara & 26 & 72,2 & 10 & 27,8 & 36 & 100 & \\
\hline Grandamulti & 6 & 66,7 & 3 & 33,3 & 9 & 100 & 2,13 \\
\hline Total & 39 & 85 & 21 & 35 & 60 & 100 & \\
\hline
\end{tabular}

Tabel 10 menunjukan bahwa grandemultipara cenderung waktu menyusui pertamanya baik yaitu sebanyak 72,2 \% lebih besar di banding grandamultipara yaitu $66,7 \%$, maupun primipara $46,7 \%$.

Sedangkan primipara cenderung tidak baik waktu menyusui pertamanya yaitu sebanyak 53,3 \% lebih besar di banding grandemulti 33,3 \% maupun Multipara yaitu 27,8\%. Hasil uji chi square didapatkan nilai $\mathrm{p}$ value 2,13 sehingga tidak ada hubungan antara paritas dengan waktu menyusui pertama pada bayi baru lahir.

Diketahui bahwa sebagian besar responden berumur dewasa (26-45 tahun) sebanyak 43 orang $(71,7 \%)$, dan sebagian lagi berumur remaja (1225 tahun) sebanyak 17 orang $(28,3 \%)$. Umur remaja cenderung waktu menyusui pertamanya baik yaitu sebanyak 70,6 \% lebih besar di banding umur dewasa yaitu $62.8 \%$.

Sedangkan umur dewasa waktu menyusui pertama tidak baik yaitu $37,2 \%$ lebih besar dibanding umur remaja yaitu $29,4 \%$.

Hasil uji chi square didapatkan nilai $\mathrm{p}$ value $0,765>\alpha 0,05$ sehingga tidak ada hubungan antara umur dengan waktu menyusui pertama pada bayi baru lahir.

Berbeda dengan pernyataan Huclock (1998) dalam Nursalam (2001) bahwa semakin cukup umur, tingkat kematangan dan kekuatan seseorang akan lebih matang dalam berpikir dan bekerja dari segi kepercayaan masyarakat. Seseorang yang lebih dewasa akan lebih di percaya dari orang yang belum

Cukup tinggi kedewasaannya. Hal ini sebagai akibat dari pengalaman dan kematangan jiwanya. Hal ini sejalan dengan penelitian Ratri (2000) bahwa kemungkinan pada umur $\leq 12-25$ tahun belum mempunyai pengalaman dibandingkan dengan kelompok umur 26-45 tahun sehingga pemberian ASI pertama kali pada kelompok umur 1225 lebih cepat. Sedangkan pada kelompok umur $\geq 35$ tahun, tergolong kelompok resiko tinggi untuk kehamilan sehingga kemungkinan ada kesulitan saat persalinan yang menyebabkan ASI di berikan lebih lama daripada kelompok umur 12-25 tahun. Tidak ada hubungan yang signifikan antara umur Ibu dengan waktu menyusui pertama kali pada bayi baru lahir pada penelitian ini.

\section{IV.Simpulan}

Rata- rata umur ibu yang menyusui pertama kali pada bayi baru 
lahir, usia remaja 12-25 tahun sebanyak 17 atau 28,3 \% dan usia dewasa 26-45 tahun sebanyak 43 ibu atau $7 \%$. Pendidikan ibu terbanyak adalah SMA sebanyak 32 ibu atau $53,3 \%$. Paritas ibu, multipara yang terbanyak, yaitu 36 ibu atau 60,0\%. Sedangkan pengetahuan ibu adalah rendah, yaitu 36 ibu atau 60,0\%.

Jenis persalinan yang tertinggi adalah spontan sebanyak 41 ibu atau $68,3 \%$. Dukungan petugas kesehatan yang negative terhadap IMD sebanyak 43 atau $71,7 \%$, sedangkan dukungan yang positif terhadap IMD sebanyak 17 atau $28,3 \%$.

Waktu menyusui pertama kali pertama kali pada bayi baru lahir di Rumah Sakit Umum Daerah Merauke yang baik 39 atau $65,0 \%$, sedangkan yang tidak baik sebanyak 21 atau 35,0 \%.

Variabel umur ibu tidak berhubungan dengan waktu menyusui pertama kali pada bayi baru lahir karena $\mathrm{p}$ value $0,765>\alpha 0,05$. Variabel pendidikan ibu tidak berhubungan dengan waktu menyusui pertama kali pada bayi baru lahir karena $p$ value $0,39>\alpha 0,05$. Variabel pengetahuan ibu tidak berhubungan dengan waktu menyusui pertama kali pada bayi baru lahir karena $\mathrm{p}$ value $0,582>\alpha 0,05$. Sedangkan variabel paritas ibu tidak berhubungan dengan waktu menyusui pertama pada bayi baru lahir dengan $p$ value $0,213>\alpha$ 0,05 .

Variabel jenis persalinan ada hubungan yang signifikan dengan waktu menyusui pertama kali pada bayi baru lahir, $p$ value $0,00<\alpha 0,05$.

Variabel dukungan petugas kesehatan tidak berhubungan dengan waktu menyusui pertama kali pada bayi baru lahir, dengan $p$ value $0,19>$ $\alpha 0,05$.

Rekomendasi yang dapat
diberikan adalah meningkatkan kegiatan konseling yang diberikan pada ibu atau calon ibu selama kehamilan dan persalinan agar memotivasi ibu untuk melakukan pemberian ASI segera setelah lahir sehingga semua ibu dengan berbagai tingkat pendidikan dapat menyusui bayinya segera setelah lahir, meningkatkan upaya mensukseskan pelaksanaan pemberian ASI segera setelah lahir dan Inisiasi Menyusui Dini (IMD) di ruang operasi untuk ibu dengan persalinan sesaria, dengan segera memposisikan bayi untuk terjadi kontak kulit dengan kulit antara ibu dan bayi. Usahaan menyusui pertama dilakukan di kamar operasi atau jika keadaan ibu dan bayi belum memungkinkan, bayi diberikan pada ibu dengan kesempatan tercepat.

\section{Daftar Pustaka}

Kementerian Kesehatan. Profil

Kesehatan Tahun 2015 http://.depkes.go.id/resources/d ownload/pusdatin/profilkesehatan-indonesia/profilkesehatan-indonesia-2015.pdf. Diunduhtanggal 12 Februari 2018.

Kementerian Kesehatan. Profil Kesehatan 2017. http://www.depkes,go.id/resour ces/download/pusdatin/profiskesehatan-indonesia/profilkesehatan-indonesia-2017.pdf. Diunduhtanggal 10 Februari 2018. 
Kementerian Kesehatan. Indikator Kesehatan SDG's

http://www.depkes.go.id/resour ces/pusdatin/profil-kesehatanindonesia/profil-kesehatanindonesia-2917.pdf.

Diunduhtanggal 29 Januari 2018.

Brinch, Jennifer. Menyusui Bayi dengan Baik dan Berhasil. Jakarta. Gaya Favorit Press.1986.

Departemen Kesehatan Republik Indonesia Dirjen Binkesmas Direktorat Gizi Masyarakat. Manajemen Laktasi Buku Pedoman bagi Bidan dan Petugas Kesehatan di Puskesmas : Depkes RI.2001.

Departemen Kesehatan Republik Indonesia. Pelatihan Konseling Menyusui: Sejak Lahir sampai Enam Bulan Hanya ASI Saja: Depkes RI 2007.

Departemen Kesehatan Republik Indonesia. Pesan-Pesan tentang Menyusui Dini (IMD) dan Air Susu Ibu (ASI) Eksklusif untuk Keluarga Indonesia: Depkes RI. 2009.

Rencana Strategi Nasional Making Pregnancy Safe (MPS) di Indonesia 2001-2020. Jakarta: Depkes RI. Artikel ini diunduh darihttp://www.who.or.id diakses tanggal 01 Februari 2018.

Ebrahim, GJ. Air Susu Ibu,Yogyakarta: YayasanEsensia Medica. 1986
Jurnal Kedokteran Trisakti. MeiAgustus 2003.Vol 22 No.22

Komalasari, Kokom. 2007. Setiap Jam Delapan Bayi Meninggal. Artikel ini diunduh dari: http://www.gloriacyberministrie s.com. Diakses tanggal 02 Februari 2018.

KESRA 2017. Ibu Negara Serukan Inisiasi Menyusui Dini. Artikel ini diunduh dari: http://www.menkokesra.go.id. Diakses tanggal 22 Desember 2017.

Notoadmodjo, Soekidjo. Pendidikan dan Perilaku Kesehatan. Jakarta: Rineka Cipta 2013.

Amalia Linda. Faktor-faktor yang Berhubungan dengan Pemberian ASI Segera pada Bayi Baru Lahir di Wilayah Kerja Puskesmas Nabire Kota. Skripsi. Depok: Fakultas Kesehatan Masyarakat Universitas Indonesia. 2012.

Ebrahim. Air Susu Ibu. Yogyakarta: Yayasan Esensia Medica.1986. 